\title{
Metajornalismo: o ofício que nasceu na sombra da Modernidade
}

Madalena Oliveira*

“A comunicação social e os jornalistas deixaram de ser a excepção. A imunidade crítica com que os jornalistas se protegiam uns aos outros, se não desapareceu, pelo menos atenuou-se. Se todas as instituições da nossa sociedade estão submetidas à observação e à crítica dos media, por que motivo as empresas mediáticas e os jornalistas seriam a excepção?”

Mário Mesquita ${ }^{1}$

Apesar de ser mais ou menos comum o entendimento de que os jornalistas não gostam de ser criticados, até porque estão bem mais habituados a criticar os outros, a verdade é que a reflexão acerca do trabalho dos jornalistas não é nada de muito novo. $\mathrm{O}$ jornalismo foi sempre uma actividade angariadora de hostilidades, ora por ser um atentado contra a literatura (Diderot, por exemplo, dizia que os jornais mais não eram do que o "pasto dos ignorantes"), ora por ousar invadir o círculo da vida privada dos cidadãos, em nome de uma liberdade de expressão, que muitos dizem ser desmesurada e irresponsável. Karl Kraus estava mesmo convencido de que a imprensa era o inimigo número um a combater, pois era a principal fonte de corrupção. Criticando o aparelho jornalístico como um todo, mais do que os jornalistas individualmente pela sua conduta, Kraus entendia que a imprensa acabou por adquirir uma posição tal que o trabalho dos jornalistas se tornou sinónimo de impunidade e de irresponsabilidade (Bouveresse, 2001). Segundo ele, o jornalista matou a nossa imaginação; "é contra a nossa vida que ele atenta com as suas mentiras" (Kraus, 2000: 190).

A implementação de mecanismos reguladores do jornalismo foi, por isso, desde muito cedo, uma exigência de homens do progresso, como Rousseau e Diderot (Lemieux, 2000). Embandeirando o objectivo de impedir a degradação intelectual do debate público, muitos foram os que, ao longo dos escassos séculos de história do jornalismo, contribuíram para desprestigiar aquele que Gabriel García Márquez disse ser "el mejor oficio del mundo".

\footnotetext{
* Doutoranda em Ciências da Comunicação, na Universidade do Minho, no âmbito de um projecto individual de investigação, financiado pela Fundação para a Ciência e a Tecnologia (magdalena@bragatel.pt).

${ }^{1}$ In Público, de 8 de Abril de 2001.
} 
Preocupados com a sua situação laboral e com o descrédito granjeado por "pseudoprofissionais", os jornalistas terão sido, no entanto, os primeiros a solicitar a regulação do sector. Segundo Cyril Lemieux, as primeiras manifestações contra a imoralidade e a promiscuidade do meio terão surgido no seio de alguns jornalistas, que não tinham vontade de ser confundidos com "pequenos repórteres conspurcados" nem com jornalistas pagos à peça com os quais tinham que concorrer regularmente (2000: 50). Ávidos de uma moral profissional que preservasse a sua dignidade, terão sido alguns jornalistas a solicitar a instauração de princípios reguladores, a fim de impedir a proliferação de condutas jornalísticas aviltantes, quer por concorrentes desleais quer por imposições da cedência da imprensa aos imperativos do mercado cadenciado pela vontade popular ${ }^{2}$.

Acusações de depravação e imoralidade, de despolitização e submissão aos poderes económico e financeiro, de irresponsabilidade, inautenticidade e manipulação ganharam nova dimensão com o aparecimento constante de novas tecnologias promissoras de cada vez mais ousadas formas de procurar e transmitir informação. Embora, na balança dos benefícios e prejuízos causados pelo jornalismo, os proveitos pareçam espontaneamente maiores, a sociedade começou a revelar-se insatisfeita e contrafeita. Exageros, subversões, atrevimentos, deslealdade, maquinação de informações, que são tudo formas impiedosas de actuação dos jornalistas, colocam frequentemente o jornalismo diante do espelho. Olhados com desconfiança, os jornalistas são, por isso, confrontados com os anseios do seu mais íntimo destinatário: o público.

Submetidos ao escrutínio ${ }^{3}$, os jornalistas perderam, como constata Mário Mesquita na epígrafe deste texto, “a imunidade crítica com que (...) se protegiam uns aos outros”. São também eles notícia, reportagem ou crónica apanágio de acções maculadas pela forma com que, cada vez mais frequentemente, enviesam a informação. É-lhes subtraída a isenção de encargos com que até ao início do século XX exerciam a veleidade de informar e, investidos do mesmo poder com que vigiam as outras instituições da sociedade, olham agora também por si próprios. Fazem do jornalismo sujeito e objecto do próprio discurso, como se entre eles e a crítica do produto do seu trabalho houvesse toda a distância que é necessária a quem về

\section{0 triunfo do interesse público}

Os ataques contra a imprensa encontraram evidência na evolução do processo de democratização e na extensão do capitalismo. Heranças do projecto moderno, a democracia e o liberalismo económico feriram de traição a fidelidade do jornalismo à sua concepção utilitarista. Ele próprio, por seu lado, fatalmente indissociável da revolução

\footnotetext{
${ }^{2}$ De acordo com o autor, a organização profissional dos jornalistas como classe, a partir do final do século XIX, foi o primeiro mecanismo a servir fins reguladores. As questões relacionadas com o acesso à profissão foram, por sinal, o motor de arranque para o estabelecimento de posteriores normas éticas de conduta.

${ }^{3}$ Nelson Traquina é um dos autores que constata o facto de "poucas profissões e poucos profissionais" serem "objecto de tanto escrutínio intensivo e tanta crítica escaldante quanto o jornalismo e os jornalistas.” (2002: 18).

${ }^{4}$ Para Merleau-Ponty, "ver é ter à distância” (Ponty, 1992: 26).
} 
tecnológica que inaugurou a sociedade de informação no século XX, condenou à corrosão os seus mais radicais valores: verdade e imparcialidade.

Leal às promessas dos avanços tecnológicos e respeitando as leis da oferta e da procura impostas pelo mercado, o jornalismo perdeu-se dos seus valores e critérios de actuação e achou-se desvirtuado na sua essência. Sem ingenuidade, cedeu às tentações do progresso e da nova sociedade industrial e capitalista, mas a sistemática submissão da actividade jornalística aos imperativos do lucro económico e a consequente transfiguração da informação num produto comerciável tornaram impossível o pleno exercício da liberdade de expressão e comprometeram a liberdade de imprensa. A crescente industrialização e a tendenciosa concentração da propriedade dos meios de informação comportaram inadvertidamente efeitos perversos "que ameaçam a qualidade, a diversidade e a integridade da informação jornalística" (Bernier, 2001). Os danos causados pelo ditame da ordem capitalista só agravaram a má imagem dos jornalistas junto das elites, pois, se é verdade que permitiu o acesso a novas tecnologias, também o é que desencadeou uma competição desenfreada e assanhados conflitos de interesses.

A verdade, porém, é que ao jornalismo foi reconhecido desde muito cedo um poder temido por uns, cobiçado por outros. Temido pelos intelectuais e pelas elites políticoculturais pela sua alegada ligação à propaganda política. Receado ainda pelos poderes convencionais (legislativo, executivo e judicial), pela ameaça do pacto de vigilância com a opinião pública. Esse foi, aliás, o papel que os utilitaristas (como Jeremy Bentham e John Stuart Mill) defenderam para a imprensa: o de ser o veículo privilegiado de expressão da opinião pública, enquanto instância de controlo social. E finalmente cobiçado por políticos ávidos de acesso ao espaço público mediatizado, por homens de negócios certos do valor económico da informação e pelo público expectante da defesa dos seus interesses.

$\mathrm{Na}$ acepção contemporânea, o jornalista é também esse "actor social cuja utilidade reivindicada é a de servir o interesse público". Segundo Bernier, ele deve assumir certas responsabilidades que visem "procurar e difundir informações verídicas que ajudarão o conjunto dos cidadãos de uma sociedade a fazer, em todos os domínios da vida contemporânea, escolhas esclarecidas com vista a melhorar as condições de vida" (Bernier, 1995: 2). Mas de outros poderes se pode ainda, falar, em relação ao poder jornalístico: o poder de participar activamente na definição e na construção da realida$\mathrm{de}^{5} \mathrm{e}$ o poder de decidir a quem dar a voz.

A consciência desta autoridade, concedida, por um lado, pela sociedade e, por outro, auto-promulgada pelos próprios jornalistas acabou por dar lugar também a uma consciência dos seus efeitos, nomeadamente das degenerações dos fundamentos de onde o jornalismo se reclama. Constantes atropelos éticos justificados pela ânsia de informar a qualquer custo e uma certa promiscuidade profissional desencadearam a necessidade de chamar os jornalistas à ordem. Virando-se o feitiço contra o feiticeiro, o

\footnotetext{
${ }^{5}$ Esse é o poder que teorias como as do agenda setting, do gatekeeper ou do news making reservam para o jornalismo desde meados dos anos 60 .
} 
jornalismo passou de controlador dos abusos dos poderes legislativo, executivo e judicial, para potencial abusador ele próprio ${ }^{6}$, ou seja, susceptível de ser vigiado e regulado.

Uma sistematização dos alicerces da crítica ao jornalismo entroncará, necessariamente, nestes dois aspectos concomitantes: a liberdade de imprensa, ansiosamente defendida pelos adeptos da democracia; e a liberdade do mercado, agitada com impaciência pelos mais diversos interesses particulares. Uma e outra são a base da angústia que atormenta os jornalistas. Por um lado, a imposição de servir o interesse público e de providenciar informação que garanta a saúde da democracia e o exercício consciente da cidadania; por outro, o imperativo de servir o interesse económico que sustenta tão altruístas ambições. Escravizados pelo público e pelos homens de negócios, os jornalistas vivem assim o embaraço de não poder abraçar dois ideais e de, por isso, serem confrontados com a responsabilidade das suas condutas.

Os novos leitores-consumidores (que são também os ouvintes-consumidores e os telespectadores-consumidores), sentenciadores de uma espécie de veredicto popular, tornaram-se mais exigentes e às críticas de superficialidade, lançadas pelas elites intelectuais, juntaram as da falta de qualidade, de corrupção e de subjugação a interesses particulares. A concorrência entre os meios de comunicação social, que atravessa todos os suportes, da imprensa escrita aos meios audiovisuais, nomeadamente a Internet, tornou as estratégias de acção mais ferozes, mas também mais evidentes, provocando com frequência uma indisfarçável confusão entre informação e criatividade artística. Muitos são, por isso, os que apelam aos jornalistas para que se restrinjam à missão que lhes confiámos: a de reproduzir a realidade, no sentido mais restrito da expressão, deixando a produção dos factos para os outros que entendem ser os legítimos agentes sociais.

Poderemos, pois, dizer que nem a teoria económica liberal se revelou suficiente para garantir a auto-regulação e correcção de excessos nem a sua congénere concepção do livre mercado de ideias se mostrou bastante para fazer emergir a qualidade e a profundidade do trabalho jornalístico. Neste sentido, não consideraremos abusivo dizer que a modernidade e as suas dimensões institucionais marcam a exigência de dispositivos de regulação associados às novas formas de vida. Anthony Giddens não hesitaria em inscrever esta exigência no âmbito das consequências da modernidade. Examinar e reformar o jornalismo mais não seriam, segundo Giddens, senão práticas da reflexividade que caracteriza, em seu entender, a vida social moderna.

\section{Accountability. o imperativo ético}

Marc-François Bernier refere-se a "metajornalismo" e define-o como "o tratamento jornalístico das práticas dos jornalistas e das empresas mediáticas" (cit. por Mesquita - DN, 8 de Abril de 2001), podendo o conceito envolver todas as modalidades

\footnotetext{
${ }^{6}$ Este parece ser também o entendimento de Mário Mesquita, ex-provedor dos leitores do Diário de Notícias que, na "Crónica do dia zero" (DN, 27 de Janeiro de 1997), admitiu que "a imprensa era e continua a ser um meio de defesa contra os abusos de poder, mas também ela pode abusar dos poderes que possui”.
} 
formais e investigativas do jornalismo, desde a notícia ao comentário. Para este autor canadiano, a liberdade do jornalismo implica "estar plenamente consciente das consequências do seu trabalho", porque "negá-las ou ocultá-las não é um acto de liberdade; será tanto uma confissão de incompetência como um sinal de carência ética" (Bernier, 1995: 2). E quer a incompetência quer a falta de ética podem significar custos pesados em termos de perda de confiança e credibilidade. Os jornais sabem-no bem e começam a perceber que "é do seu próprio interesse, bem como do interesse dos leitores, idealizar meios efectivos de providenciar formas de prestar contas" (Neil Nemeth ${ }^{7}$ ). No original, em inglês, o termo é bem mais incisivo: accountability, que é, de acordo com David Pitchard, "o processo pelo qual se espera que as organizações mediáticas sejam obrigadas a prestar contas das suas actividades aos seus constituintes" (2000: 2), sejam eles os membros da audiência, os anunciantes, as fontes de informação ou outras organizações pares e órgãos reguladores. $\mathrm{Na}$ acepção de Pitchard, três etapas são necessárias para desencadear um processo escrutinador ${ }^{8}$ : primeiro, identificar um problema; depois, culpar os media pela situação identificada; e, finalmente, exigir uma correcção. Assim sendo, ainda que admitamos que, uma ou outra vez, os jornalistas tomem, por si, a iniciativa de reflectir publicamente sobre a sua conduta, o público é, neste modelo, um elemento fundamental do processo de escrutínio, na medida em que é também por ele e para ele que os jornalistas desmontam o seu trabalho.

Para Denis McQuail são quatro as facetas do processo: ser escrutinável por alguém, por alguma coisa, na base de alguns critérios e com um grau variável de exactidão (McQuail, 1997)9. É, pois, evidente que um processo escrutinador é sempre desencadeado com base em casos específicos, em que a responsabilidade social seja, ou deva ser, assumida pelos jornalistas e pelas organizações que integram. Para McQuail, a relação entre os media e o público pode ser caracterizada, a este nível, por três tipos de enquadramento. Um primeiro quadro, que o autor entende ser regulador e legal, estabelece os princípios básicos e regras de fundo para a operação das instituições mediáticas e estabelece direitos e deveres para os indivíduos em relação aos media. A lógica relevante e o discurso são de carácter legal, racional e administrativo. No âmbito de um quadro financeiro ou de mercado, exalta-se o facto de o público poder reagir também de forma indirecta. Podendo penalizar os media pelo seu mau desempenho mediante a simples opção de lhes renunciar (não comprando o jornal ou desligando a televisão), o público rege-se assim pelas leis da oferta e da procura, que asseguram, segundo McQuail, “um equilíbrio aproximado entre as necessidades e os interesses dos consumidores e aqueles que consomem e entre os interes-

\footnotetext{
${ }^{7}$ In Pitchard, David (org.), Citizens, Ethics and Law-Holding the Media Accountable.

${ }^{8}$ Apesar da dificuldade de encontrar na língua portuguesa um vocábulo específico para o termo accountability, optamos por nos referir a escrutínio, que é, entre nós, provavelmente a palavra que mais se aproxima do significado na sua origem inglesa.

${ }^{9}$ McQuail distingue, no âmbito do processo escrutinador, duas vias possíveis: a de uma relação adversa, motivada por ofensa ou dano causado pelos media (liability) e a da prontidão dos jornalistas para o debate, normalmente acerca da qualidade do seu trabalho (answerability).
} 
ses da indústria mediática e os da sociedade em geral” (1997: 521). Tipicamente democrática-liberal, a lógica deste quadro põe em evidência a liberdade, a eficácia, a escolha, os proveitos e as preferências da maioria. Por último, o quadro que particularmente nos interessa no âmbito deste trabalho: o da responsabilidade pública. Num discurso caracteristicamente normativo e julgador, os objectivos deste enquadramento do escrutínio a que os media se sujeitam prendem-se, de acordo com o autor, com "uma preocupação primária com a sociedade, o bem público e com os propósitos ideais da informação, opinião e cultura” (1997: 522).

Sugerindo que a auto-regulação é o mecanismo mais adequado para garantir a liberdade de expressão como condição basilar da actividade dos jornalistas, McQuail aponta ainda dois objectivos do escrutínio dos media: por um lado, prevenir ou limitar os danos que os media podem causar e, por outro, promover resultados positivos para a sociedade, nomeadamente no que concerne aos contributos dos media para o trabalho dos políticos e outras instituições sociais. Universalmente responsáveis, como todos os domínios da vida social, pela garantia dos direitos dos indivíduos e, particularmente tributários das condições de uma democracia efectiva, os media têm, numa sociedade cujo firmamento gira à sua volta, o encargo de atender às exigências de uma deontologia que se constrói “dia a dia, caso a caso, num diálogo que deve envolver jornalistas, leitores, estudiosos dos media, 'fontes', provedores e todas as demais partes interessadas" (Mesquita, 1998: 16)".

Uma reflexão deontológica por si, porém, não bastará para “julgar” condutas profissionais. Marc-François Bernier considera que, deixada a si mesma, a deontologia se cristaliza; "sedimenta-se e nega os seus fundamentos para se auto-justificar sem fim" (1995: 23). Assimilando a deontologia ao cristal, “cuja estrutura molecular estável resiste a pressões do ambiente”, Bernier entende que a deontologia em si não é adaptável a situações particulares. "É a reflexão ética que permite descristalizar a deontologia e lutar contra a sua sedimentação" (ibidem). Não sendo codificável por definição, a ética é o cruzamento filosófico onde se discutem e hierarquizam os valores e princípios que inspiram as regras morais (entendidas como uma espécie de deontologia cívica) e deontológicas (enquanto regras de conduta profissional). A reflexão ética seria, por esta via, a resposta à crise do jornalismo, fundado na mesma identificação que assombra a modernidade: a do espaço público como um espaço de palavra.

\section{Metajornalismo: 0 imperativo político}

Apesar de, desde o início da sua massificação, se ter percebido que o jornalismo não era uma qualquer forma de arte, gratuita e ficcional como todas as outras, só a partir de 1947 é que oficialmente se atribui aos media uma responsabilidade social nas organizações. Para isso parece ter sido determinante o relatório da Comissão da Liberdade de Imprensa (Comissão Hutchins), que, entre outras considerações, sugere aos media que procurem lançar-se num vigoroso criticismo mútuo como meio de promover o escrutínio (Nemeth, 2000). No entanto, só duas décadas mais tarde 
é que um jornal americano (o Louisville Courrier-Journal) decide criar a figura do "provedor dos leitores", adoptando o conceito sueco de ombudsman. ${ }^{10}$ Entendida por uns como uma estratégia de marketing e por outros como uma forma de dizer aos leitores que o jornal não teme o confronto com os seus próprios erros, a opção por um ombudsman, por ora quase exclusiva da imprensa, parece ser de reconhecida importância, num tempo em que a fé do público na exactidão dos media enfrenta um processo de erosão (Gestlin, 2000). Tom Rosenstiel, director do Project for Excellence in Journalism (cit. por Gestlin), entende que há um grande sentido da crise e da necessidade de mudança nos jornais e que o papel dos ombudsmen está para além da protecção da imagem do jornal na comunidade; "é uma questão de credibilidade".

Para Mário Mesquita, o ombudsman "possui apenas um poder de influência e de palavra”. Não tendo força coercitiva, a voz crítica dos jornalistas acerca do seu próprio trabalho (não só pela pena do provedor dos leitores, mas também noutros espaços escassos mas privilegiados como editoriais, colunas de opinião, fóruns de discussão, debates televisivos...) fia-se acima de tudo na performatividade do discurso. "Simultaneamente batalha e arma, estratégia e choque, luta e troféu ou ferida, conjunturas e vestígios, encontro irregular e cena repetida" (Foucault, 1969: 8, cit. por Martins, 2002: 26), o discurso é, lembra-nos Moisés Martins em palavras de Foucault, "aquilo por que lutamos, o próprio poder de que procuramos apoderar-nos" (Foucault, 1971: 12, cit. por Martins, 2002: 26)". O que, concretamente, será o mesmo que dizer que o discurso metajornalístico mais não será do que aquilo por que os jornalistas lutam, o poder de si próprios de que procuram apoderar-se, para controlar o controlo que exercem sobre as instituições sociais.

Reformulando a proposta de Bragança de Miranda, a resposta à crise que abisma o jornalismo teria antes de passar pela ideia de política, porque essa é, para o autor, "a resposta milenar à situação de perigo" (Miranda, 1997: 38). A política, entendida como agir livre, "é prática, emerge da experiência" (ibidem). A ética não; "antes de ser uma teoria é uma estratégia de normalização do agir, uma forma de controlar o ethos do agir" (Miranda, 1997: 130). Convocamos a este pretexto as considerações do autor acerca da pragmática do meta. Para Bragança de Miranda, mais do que uma "mera mudança de nível" e "não se confundindo também com a procura do 'oculto", a categoria de metapolítica (no nosso caso, metajornalismo, como um modo de metapolítica) trata "tão-só de compreender os processos que fazem de uma dada 'figura' algo de evidente".

O recurso à categoria do metajornalismo é, tal como o recurso à categoria de metapolítica em Bragança de Miranda, imperativo e revela estar na alçada da necessidade de mergulhar na imanência da actividade jornalística para lá interrogar os

\footnotetext{
${ }^{10}$ Há, contudo, indicações de que mecanismos semelhantes ao do ombudsman - de atenção às reacções manifestadas pelo público - tenham surgido primeiramente no Japão. Ainda que especialmente significativos, não caberão neste artigo os detalhes com que se escreve a história dos ombudsmen. Optamos por abreviá-la para nos determos num curto ensaio acerca dos fundamentos das estruturas de rastreio do discurso jornalístico.
} 
processos e as condições de que depende a sua produção, isto é, em última instância, de que depende o seu agir, pelo menos aparentemente livre. Intervindo no discurso, a categoria metajornalística tem a incumbência de desconstruir os sentidos constituídos para neles encontrar as leis que os regulam, sejam elas intrínsecas à origem histórica do jornalismo ou administrativamente instituídas na esteira da vida social moderna.

O metajornalismo, de novo tal como a metapolítica, “é um 'efeito do efeito"” (Miranda, 1997: 140). Resulta, como longamente o descrevemos já, da consciência dos efeitos do jornalismo. Não sendo possível um retorno ao grau zero do jornalismo, o metajornalismo surge como a possibilidade de ir lá, aonde os seus efeitos efectivamente se geram, para apreender a sua contingência. Fragmentado como toda a experiência humana, o produto jornalístico torna imperiosa a sua reconstituição pelo próprio discurso.

Argumentos meramente éticos para balizar a experiência jornalística tendem a absolutizar o discurso e a encerrar tudo no fundamentalismo da letra das regras. Correspondendo a condições universais, estabelecidas a priori, a ética é do domínio do transcendental. Mas a experiência jornalística não se confina no estabelecido universalmente. A experiência jornalística, como toda a experiência humana, é contingente e iminentemente conflituosa. Vive em tensão permanente, porque relações há que a superam: são as relações de mediação entre a realidade e o público. As mesmas relações que tendem a conferir-lhe uma certa ordem, conferindo-lhe também as condições da sua acção.

O discurso metajornalístico é, pois, um discurso ambicioso. Ele visa aceder, vigilante, aos abatimentos morais e aos cansaços do discurso mediático. Apeteceria talvez dizer, com o realismo de Eça de Queirós, que o metajornalismo não tem repouso, porque, parafraseando o escritor, se ele repousasse ninguém velaria pelos que dormem (Eça de Queirós) ${ }^{11}$. E o certo é que, como bem o entendeu Guy Debord, na sociedade de espectáculo que continua a ser a nossa, não exprimimos senão a nossa vontade de dormir.

Categoria crítica por excelência, o metajornalismo é a promessa moderna de resposta aos perigos do jornalismo, sobretudo ao perigo de continuarem a abundar, como anotou Joaquim Fidalgo, “acusações (justas em nosso entender) de que uma instituição socialmente tão poderosa como é um jornal (nós acrescentamos, todos os media de informação) escape com facilidade a quaisquer mecanismos democráticos de controlo", arriscando-se a adquirir "um estatuto próximo da impunidade" 12 . Mas é também a resposta ao perigo de absolutização da realidade. $\mathrm{O}$ discurso jornalístico não tem o dom de totalizar a experiência humana do mundo, porque ela é em si mesma intotalizável.

Ousando emprestar um olhar sobre a realidade, o jornalismo é, no entanto, sujeito aos olhares de suspeita daqueles a quem parecia apenas querer prestar um serviço. Olhares às vezes apreciadores, outras vezes depreciadores. Assim é quando se joga no círculo das nossas mais singulares formas de ensaiar uma experiência do mundo.

\footnotetext{
${ }^{11}$ "Distrito de Évora", nº 1 (6 de Janeiro de 1867)

${ }^{12}$ Coluna inaugural de Joaquim Fidalgo enquanto "Provedor dos Leitores", Público, 3 de Outubro de 1999.
} 


\section{Referências bibliográficas:}

Bernier, M.-F. (1995). Éthique et déontologie du journalisme, Québec: Les Presses de L'Université Laval. Bouveresse, J. (2001). Scmock ou le triomphe du journalisme - La Grande bataille de Karl Kraus, Paris: Éditions du Seuil.

Getlin, J. (2000). 'The Critics: Ombudsman', Columbia Journalism Review.

Giddens, A. (1998). As Consequências da Modernidade, Oeiras: Celta.

Kraus, K. (2000). Cette grande époque, Paris: Éditions Payot \& Rivages.

Lemieux, C. (2000). Manvaise presse - Une sociologie compréhensive du travail journalistique et de ses critiques, Paris: Éditions Métailié.

Martins, M. (2002). A Linguagem, a Verdade e o Poder - Ensaio de semiótica social, Lisboa: Fundação Calouste Gulbenkian/FCT.

McQuail, D. (1997). 'Accountability of Media to Society', European Journal of Communication, vol. 12 (4), pp. 511-529.

Merleau-Ponty, M. (1992). O Olho e o Espírito, Lisboa: Vega.

Mesquita, M.(1998). O Jornalismo em Análise - A coluna do Provedor dos Leitores, Coimbra: Minerva Miranda, J. B. (1997). Política e Modernidade, Lisboa: Edições Colibri.

Pitchard, D. (org.) (2000). Citizens, Ethics, and the Law - Holding the Media Accountable, Bloomington: Indiana University Press.

Traquina, N. (2002). O que é Jornalismo, Lisboa: Quimera.

Referências da imprensa:

Distrito de Évora, n. ${ }^{\circ} 1,6$ de Janeiro de 1867.

Fidalgo, J. (1999). 'Uma ponte com dois sentidos', in Público, 3 de Outubro de 1999.

Mesquita , M. (1997). ‘Crónica do dia zero’, Diário de Notícias, 27 de Janeiro de 1997.

\section{Resumo}

Desprestigiado ao longo da história, quer pelo não reconhecimento do seu papel quer pelo descrédito do seu desempenho, o jornalismo foi sempre um alvo fácil da crítica, primeiro dos intelectuais, agora da sociedade em geral. Em permanente crise de legitimação, o jornalismo é hoje cada vez mais submetido à observação e vigilância do público. Chamados a prestar contas da sua actividade, os jornalistas são confrontados com a responsabilidade social do seu trabalho. Abrem a reflexão deontológica ao público, multiplicando as práticas que denominamos metajornalísticas. São os efeitos da modernidade e das suas dimensões: vigilância, capitalismo e industrialismo.

\section{Abstract}

Having been depreciated during the History, by the unknown role it plays or by the unreliability of its performance, journalism was always an easy target of criticism, first by intellectuals, now by the society in general. Being in permanent crisis of legitimacy, journalism is today more and more submitted to public observation and vigilance. Called to account for their activity, journalists have to face the social responsibility of their work. They make the deontological reflection public, multiplying practices that we name by metajournalistics. It is the effect of the modern age and its dimensions: vigilance, capitalism and industrialism. 